\title{
¿SERÁ YA TODO SOLAMENTE SILENCIO?
}

\author{
Francisco CAUDET \\ Universidad Autónoma de Madrid
}

\section{RESUMEN}

La traición y el regicidio o crimen de Estado de Macbeth sirve de punto de partida para tratar del levantamiento militar de 1936 contra la legitimidad republicana y lo que siguió a abril de 1939: represión en el interior (cerca de doscientos mil fusilados republicanos) y el exilio (en un primer momento, medio millón). Esta tragedia colectiva y la necesidad de ser narrada, así como los problemas narratológicos que ello suscita, son cuestiones planteadas también en este artículo.

Palabras clave: represión, exilio, narración, Guerra Civil, posguerra.

\section{ABSTRACT}

Taking the perfidy and the regicide in Macbeth as a starting point, this paper centres on the military raising of 1935 against the republican legitimacy and the circumstances later to 1939: repression and exile. It also examines the need to relate this collective tragedy and the narrative problems caused bay this need.

Key words: repression, exile, story, Civil War, postwar.

Era un asesino deseo, Macbeth, el que anidaba en ti y en tu temblorosa mano. Tu perturbada mente había llenado tu mano, Macbeth, de demasiada asesina ansiedad. A esa mano tuya la impulsaba un enfermizo deseo de ser y habitar únicamente un tiempo sin culpa, un tiempo de sangre sin memoria, un tiempo de muerte y desolación sin tiempo. Un tiempo sin ayer ni mañana para la culpa deseabas. Un tiempo sin sucesión de horas y días, un tiempo de olvido deseabas.

Con tu mano, Macbeth, con tu asesina mano deseabas tú asesinar el tiempo, ese era tu deseo, tu único deseo, tu obsesivo deseo, tu enfermizo deseo, tu asesino deseo. 
Con tu mano, Macbeth, con tu mano apretada a la daga, azuzada tu enfermiza mente por el pastoso aire de una boca, acaso una pintarrajeada mueca, que susurraba a tus espaldas una plegaria diabólica, te has quedado asido a ese instante eterno en la espera y en el acto, tiempo suspendido en el aire que se desea eterno, que se desea no sea nunca acto y al cabo irremediablemente es acto, pasaje, tránsito, tiempo, tiempo que se sucede, tiempo que se vuelve conciencia o mirada o tan simplemente una palabra que grita en la noche y aporrea el cerebro:

How is't with me, when every noise appalls me?

What hands are here? Ha! They pluck out mine eyes!

Will all great Neptune's ocean wash this blood

Clean from my hand? (Macbeth, II, II).

El tiempo es, no lo pudiste tampoco tú, Macbeth, sortear, conciencia, palabra. El tiempo, que necesitabas detener y acallar, es siempre, acaba siendo siempre, un impertérrito narrador. Lo es, lo acaba siendo siempre, para que tú, Macbeth, no puedas nunca borrar los rastros de sangre en tus ensangrentadas manos.

Narrar, el movimiento de la palabra, o la palabra en movimiento, es un camino, una meta. De ahí acaso el rechazo de lo superfluo, de «lo que se encuentra mal hilvanado» y que por ello «resulta difícil de entender» (Aristóteles, 1993: 74-75). Rememorar, o sea narrar, es, pues, tejer, trenzar, tramar. O accionar, poner en marcha una sintaxis, un engranaje de aire, a veces el carraspeo de una pluma, que alimentándose de un cúmulo de fragmentos, de historias sin aparente relación o con expresa relación, configura un sistema de energías y de tensiones, de compulsiones, y también de resistencias, cuyo punto último de llegada es un quimérico horizonte plagado de sentido.

Los recuerdos, que las más de la veces emergéis inesperadamente, a trompicones, ¿sois el espíritu o la materia que nos conforma y nos define, que nos señala de dónde venimos, quiénes hemos sido, quiénes somos o ya no somos?

Rememorar, como narrar, es una forma de enseñar y de cubrir y de pausadamente, sin prisa alguna, morosamente volver a mostrar, o con prisa, a trompicones, atropelladamente, tal las aguas de un río van transcurriendo lentamente por un cauce, rozando casi aquietadas las sinuosas riberas, o toman carrerilla y sorpresivamente se abalanzan sobre las pronunciadas riberas de los meandros, tal la pluma del escritor, una geografía, un cauce aquietado, que, de pronto, inesperadamente, cambia de ritmo, impulsa, da fuelle a las aguas, a las palabras, y se deslizan vertiginosamente...

Por estos o similares procedimientos, las palabras tejen un sentido que tiene una dimensión colectiva, pues ese sentido tiene como destinatario a individuos 
que forman colectividades, grupos de ciudadanos. Las palabras construyen discursos sobre las expectativas del ayer y del hoy, siempre con el concurso de individuos formados o modelados por el grupo, individuos que con esa mediación tienden a un mañana imaginario cuya urdimbre se remonta a otro tiempo, el ayer y el precario hoy. Así, las palabras fundan discursos sobre el humus de la necesidad. Así, las palabras inventan, trastruecan el ayer y el hoy. Son un torbellino de gestos, de sentidos. Suya es la potestad de articular, de crear, de inventar un lenguaje que es, ha de ser siempre, de uno y de todos; que es, ha de ser siempre, propio y comunal.

Rememorar puede ser -ia qué negarlo?- una tergiversación, una deformación. Otra vez, la daga de Macbeth. Esa daga que simboliza la peor de las maldiciones. El mundo está, sí, poblado por todas partes de Macbeths y de ladies Macbeth. Porque prolifera desde siempre la necesidad de inventar una genealogía, un pasado. Con esa argamasa inventada nos poblamos - ¿quién escapa a ello?- de fantasmas. Somos narraciones, una invención que puede clavar la daga en la garganta del ayer, que puede condenar al tiempo pasado al silencio. La predisposición a remediar ese hecho -el «I have done the deed» (Macbeth, II, II)-, prestándole al pasado silenciado o tergiversado nuestra voz, nunca ha de resucitar lo que fue y ya no es, lo que ya no será jamás. No podemos viajar por el tiempo, no podemos volver a lavar nuestras ensangrentadas manos dos veces en la misma agua. Somos tiempo, tránsito, una daga suspendida que acaba cayendo como los granos de arena, tiempo somos que se desparrama, que cubre y ahoga, que difumina cuanto ha sido y ya no es ni será. Y la conciencia de lo que fue nos atrapa en sus redes, nos inmoviliza. Hasta cuando corremos, hasta cuando pensamos estar huyendo, hasta cuando tenemos la certeza de haber huido del ayer.

El ayer, una imagen en nuestro cerebro. Una imagen que nos impulsa a recobrar lo fugaz, lo que fue. Imagen que pasamos junto con otras en una moviola, recuerdos en movimiento. Y así lo que fue ya es solo cuento, palabras. Materiales de una hipotética construcción. La memoria está demasiado a menudo huyendo de sí. Por las desoladas llanuras del ayer se pierden demasiados recuerdos. Tal esos oscuros pájaros que siempre están emigrando de su soledad, se pierden, sí, demasiados recuerdos.

Alada es la memoria, fragmentaria es la estructura de su vuelo. Un vuelo que necesita, como nosotros, una dirección, un sentido. Constituir un todo unitario. Un todo unitario, un vuelo con una orilla, con una meta.

Diverso, fragmentario y unitario es el Guernika de Picasso, ese mítico fresco de la guerra civil española, como lo es El laberinto mágico de Max Aub (Caudet, 2000), ese fresco literario sobre la diáspora de los republicanos. Cada poema, cada cuento, cada novela, cada obra de teatro, cuanto escribió y dijo Max Aub 
desde que abandonó a la fuerza España en los primeros meses de 1939, es un cúmulo de trazos, de pinceladas, un ir llenando un lienzo de colores y formas, de manera esforzada, paciente, voluntariosa, hasta que nada más cupiera en él, pero sabiendo de la imposibilidad de toda empresa que pretenda abarcar lo inabarcable. Ese magno proyecto de construir, palabra a palabra, trazo a trazo, pincelada a pincelada, una totalidad que fuera la expresión de la experiencia individual de Max Aub y, a la vez -El laberinto mágico comparte ese proyecto con el Guernika-, la del resto de los republicanos. Porque, a fin de cuentas, si algo evidencia de manera paradigmática los desastres de la guerra civil, de la represión y el exilio posteriores, es que se trata de un tiempo marcado por el sello de lo colectivo y, por ello, aunque solamente fuera por ello, también su reconstrucción ha de tener esa marca. Como concluye Emilio Lledó en Memoria de la ética (1994), lo colectivo acaba siempre conformando la estructura de lo real.

La represión franquista se cebó, tan irrefrenables fueron tras la victoria sus ansias de venganza, en la población civil. Hartmut Heine, que parte del principio de que «la liquidación física del enemigo político o su neutralización temporal mediante el encarcelamiento o el destierro casi siempre han sido los fundamentos sobre los que los regímenes autoritarios han establecido o consolidado su poder», observa, con todo, que a diferencia de en otros países, en el caso del franquismo «nos encontramos ante una situación donde a una fase de intensa represión, que se prolonga a lo largo de toda la guerra, le sucede otra etapa no menos cruenta, a pesar de que el enemigo ya ha sido militarmente derrotado» (Heine, 1990: 309).

Rafael Abella recuerda, en uno de sus estudios sobre la vida cotidiana en la España de posguerra, que si el país había estado «dividido en la guerra, todavía se dividió más en la paz», cohabitando, como si fuera lo más natural del mundo, «los afortunados que vivían en la ignorancia del carácter verdadero de la represión emprendida» $\mathrm{y}$ «los que la estaban sufriendo en carne propia o en la de sus allegados» (Abella, 1978: 53). En la prensa, ante la indiferencia o asentimiento de los primeros -continúa diciendo Abella-, no paraban de aparecer noticias del continuo goteo de ejecuciones. Así, en un artículo de Las Provincias de Valencia, aparecido poco después de terminada la guerra, se afirmaba, dejando constancia de esa situación: «La Justicia de Franco, la de la Nueva España, severa e imperturbable, va cumpliendo su cometido día a día, hora a hora, separando de la sociedad a aquellos que por sus delitos y crímenes constituyen un peligro y una mancha para la misma» (Abella, 1978: 56).

Las cifras de la represión franquista en los primeros años de la posguerra, aunque no faltan quienes pretenden minimizarlas - una forma, entre otras muchas, de hacer la apología, de manera consciente o subliminal, de la dictadura-, osci- 
lan en torno a un número de víctimas no inferior a 150.000. Esta es la cifra que baraja Hartmut Heine. Rafael Abella, por su parte, señala: «Tan sólo hay un dato -que damos con ciertas reservas- proporcionado por el Ministerio de Justicia que habla de 192.684 personas "ejecutadas o muertas en prisión"; entre 1939 y 1944, lo que deja la incógnita de óbitos debidos a una u otra causa» (Abella, 1978: 56). Josep Fontana destaca de la represión franquista su naturaleza y función política. Las estadísticas que baraja de ejecuciones evidencian que «predominan de manera aplastante los campesinos y obreros» (Josep Fontana, 1986: 24).

La represión, por encima del debate en torno a las cifras, había sido, durante y después de la guerra, la estrategia del régimen para, primero, alcanzar el poder y, luego, mantenerse en él y lograr su legitimación. De ahí que pretender minimizar o incluso negar el uso y abuso indiscriminado de la fuerza por el régimen franquista, y para esas metas, resulte, por un lado, históricamente insostenible $y$, por otro, tal actitud pone de manifiesto una complicidad con ese tenebroso pasado.

Hay, además, quienes todavía defienden que el franquismo fue un fenómeno ajeno a la sociedad y que, por tanto, no fue expresión -amalgama o correa de transmisión- de unas ideologías e intereses económicos y de clase enraizados en sectores de la sociedad civil y religiosa. En el fondo de estos argumentos -como ocurre con el tema de la represión- hay unos propósitos de reescribir la historia del llamado eufemísticamente «régimen anterior». Pero esa reescritura apunta, sobre todo y principalmente, a rehabilitar -borrando, difuminando, haciendo ilegible, irreconocible el pasado- a los sectores de la sociedad que alentaron la rebelión militar y a cuya sombra conservaron viejas prebendas y encontraron nuevas maneras de medrar.

Frente a quienes defienden las tesis de que el franquismo fue un fenómeno sin conexión con ningún grupo social y que no tenía o representaba ninguna ideología, abogo, tal como hacen Benjamín Oltra y Amando de Miguel, por la existencia de ambas premisas, pero acentuando -añadiría yo- que la verdadera cuestión, la pregunta que hay que hacerse, es, además y sobre todo, cuáles fueron las relaciones de causa/efecto del franquismo con las fuerzas sociales, políticas, económicas y también, como no podía ser menos, ideológicas, que se amalgamaron y escudaron en él. Pues han sido esas fuerzas las que han definido, en última instancia, al franquismo. Benjamín Oltra y Amando de Miguel plantean el debate en estos términos:

El franquismo no surge, pues, como régimen de equilibrio entre «todos» los intereses de clase, sino justamente al contrario, como instrumento eficaz del bloque agrario tradicional o de su expresión política, el Frente Nacional, para «liquidar la lucha de clases». Con el ascenso del franquismo salen vencidas la clase obrera y las fracciones republicanas y liberales de la burguesía y pequeña burguesía, así como 
las diversas formaciones político-culturales de las nacionalidades hispanas (Oltra y De Miguel, 1978: 71).

Aunque el concepto «bonapartismo»-ya empleado por Tuñón de Lara en los años cuarenta (Tuñón de Lara, 1947)- pueda parecer anacrónico o exógeno al fenómeno del franquismo -o del fascismo- del siglo XX, permite llegar a Benjamín Oltra y Amando de Miguel a unas conclusiones convincentes y, en consecuencia, perfectamente asumibles:

El franquismo fue un movimiento lo suficientemente ideológico como para dar curso a la Weltanschauung de la derecha católica y lo suficientemente pragmático para saber que tenía que basarse en esas cuatro fuerzas sociales: el trono, el altar, la espada y el capital.

La función clave del instrumento bonapartista en el franquismo -extensivo ello también a los fascismos- es que sólo el instrumento militar, o el estado militarizado es garante eficaz del orden y capaz de acabar con la lucha de clases. Para ello es preciso (como señalara Adorno para definir la personalidad autoritaria) «socializar» el terror, crear una imagen pública de permanente amenaza. Thalheimer hace extensiva esta función a todo «Estado de excepción» o dictadura: «Fascismo y bonapartismo prometieron a la sociedad burguesa "paz y seguridad", pero, para demostrar que ellos son indispensables como "salvadores permanentes de la sociedad" tenían que hacer creer que la sociedad se halla continuamente amenazada, en un estado permanente de desorden e inseguridad"».

No cabe la menor duda de que el alzamiento de 1936 lo organizaron los militares, pero lo prepararon con el dinero de los burgueses y lo arroparon con las ideas de los intelectuales. Es más, la idea de rebelión fue machaconamente repetida por políticos e intelectuales desde los primeros momentos del período republicano. Y es que para hacer una guerra lo primero que hace falta es etiquetar al enemigo (Oltra y De Miguel, 1978: 78-81).

El franquismo, que tuvo la ideología de esas fuerzas que lo instrumentalizaron y que de él se sirvieron, se adaptó, al menos en un principio, al dictado de toda esta confluencia de intereses y de mentalidades que quiso salvaguardar. Pero además, el franquismo, al igual que esa amalgama de intereses y mentalidades, tuvo que replegarse a las exigencias que le impuso un mundo exterior, el de las llamadas democracias occidentales. Un mundo, de signo político distinto al franquismo, que comprendió en seguida que le resultaba muy práctico y beneficioso mantener en España el statu quo de la dictadura. Simplemente se le pidió al general que no hiciera manifestaciones estentóreas de su pasado fascista. Y así lo hizo, inventando él y su camarilla -nunca le faltaron fieles servidores- el engendro de la «democracia orgánica».

La carencia de escrúpulos o el oportunismo de adaptarse a las más variables circunstancias -es decir, el no reparar en los medios para conseguir unos finesdel franquismo y de sus valedores/cómplices no implica, en fin de cuentas, carencia de ideología ni tampoco que ésta tuviera originalidad alguna. Ni tampoco 
cabe de ello deducir que la supervivencia del régimen se debiera necesariamente a la planificación o a la sagacidad del líder. Franco, con una ideología de detrito, se fue simplemente adaptando -siempre manu militari, como si España fuera un cuartel- al ritmo de los acontecimientos.

En el interior, se afanó en desmovilizar a la población por el tosco y brutal mecanismo de la violencia. Para Juan Martínez Alier, a diferencia de otros historiadores, el hecho básico de la vida política franquista fue la feroz matanza indiscriminada de los primeros años de posguerra, cuya posterior memoria -negar o soslayar la primera premisa consigue el efecto de minar su memoria- ha tenido también efectos devastadores.

Con todo, Martínez Alier tiende a relativizar la cuestión de la desmovilización del pueblo español en aquellos años -que terminó afectando incluso a la oposición clandestina-, pues se trataba solamente de una manifestación engañosa, situacional. Según argumenta Martínez Alier, los términos «movilización» -o «desmovilización»- deben ser sustituidos por el término «consciencia dual». Término este último que, en referencia al mundo obrero durante el primer franquismo, explica así:

\begin{abstract}
No puede decirse que los obreros están conformes o disconformes con la situación, sino que es más exacto decir que están a la vez conformes y disconformes: de un lado se creen impotentes para cambiarla y, en vez de asumir esa falta de fuerza y de confesar ese miedo y de tratar superarlos, muchos prefieren tomar una actitud fatalista y manifiestan un cierto recelo ante los militantes que pretender sacarlos de esa inactividad; de otro lado, a pesar de esa calma aparente, hay una profunda inconformidad con la situación, que a veces es difícil de descubrir porque se disimula bajo esa capa de fatalismo. Hacia dónde van a ir en sus actuaciones, depende de la fuerza de la represión política y de la persistencia del miedo. Por tanto, es erróneo tomar la «despolitización» como un dato, porque puede desparecer de un día para otro (Martínez Alier, 1978: 31-32).
\end{abstract}

Esa aparente despolitización, que a muchos ha de antojárseles muy real, porque en última instancia permitió al franquismo, sobre todo en su primera etapa, la más difícil, afianzarse en el poder. Y también permitió a sus valedores -hay que establecer estas relaciones, porque en ellas está la explicación, insisto una vez más, del franquismo- tener controlada a la clase obrera. José M. ${ }^{2}$ Marcet, en Mi ciudad y yo. 20 años en una alcaldía, 1940-1960, dejó de ello, aduciendo el ejemplo de los empresarios catalanes, una muy patente constancia:

El obrero, aunque no exteriorizaba sus pensamientos, tenía la sensación y el encubierto temor de que no tardaría en caer en una nueva era de esclavitud en el trabajo, pues suponía que le sería impuesto de manu militari. Lo curioso es que tal mentalidad no se encontraba solamente entre los obreros. Algunos empresarios de regreso a la ciudad se dispusieron a hacerse cargo de sus industrias con la seguridad de que en lo sucesivo tendrían a los trabajadores férreamente sujetos a sus pies (Molinero, 1990: 21).

Anales, 21, 2009, pp. 39-66 
El franquismo acabó creando y alimentando una tupida red de intereses y complicidades que se fue ampliando a los distintos niveles de la sociedad. Al fin, todos debían algo al régimen, todos dependían de alguna forma del régimen, todos estaban más o menos vendidos al régimen. Esa dejación de la soberanía e integridad individual convirtió, como no podía ser de otro modo, en súbditos sumisos -y, claro, también en beneficiarios del sistema, cuya complicidad variaba según el nivel del beneficio- a los que, de distintas formas y maneras, apoyaron la rebelión militar; y, asimismo, a los que luego se subieron a ese carro. De ahí que todos hayan querido, en los últimos años, saltar de ese carro, como si nunca hubieran estado subidos en él, como si nadie hubiera estado implicado en la dictadura franquista.

Pero complicidad y dejación de soberanía e integridad personal era el peaje que pagar. Las dictaduras son producto de una situación corrupta que termina generando -como cabe deducir de estas palabras de Max Gallo- más y mayor podredumbre:

Además de los grandes terratenientes, de los grupos financieros, de la Iglesia, de los
militares de alta graduación que gozan de la más amplia libertad de acción, el régimen
ha creado una tupida red de complicidades que penetra en la población: antiguos
falangistas que no deben su puesto en un ministerio más que a su pasado político, por-
teros, guardianes de museos, funcionarios ligados al poder por una corrupción general
de la que obtienen algunas migajas. Solidarios también del franquismo por miedo a
una revancha de los republicanos vencidos, y tanto más prestos a defender al Caudillo
en cuanto que son responsables de las venganzas ejercidas sobre los vencidos, ocupan
puestos elevados en la jerarquía y temen represalias a la medida de las que ellos ejer-
cieron. Cuando un republicano cae bajo las balas del pelotón de ejecución, el franquis-
mo no se limita a matar a un enemigo desarmado, prisionero político ya vencido, sino
que también encadena a todos los que participan más o menos voluntariamente, que
van a sentirse y creerse cómplices, todos los que, piezas más o menos conscientes de
la máquina, jueces, guardianes de prisión, escribanos, soldados de pelotón, oficiales,
que han participado en la represión de una u otra manera, o simplemente consentido
la ejecución. Y en España se ha matado mucho y se continúa ejecutando, luego hay
muchos cómplices, que son también víctimas (Gallo, 1971: 147).

Por estos u otros derroteros, han ido abriéndose paso unas lecturas del pasado que conducen a tres negaciones y a una afirmación: el franquismo no tuvo ideología; el franquismo fue un fenómeno autónomo, sin conexión con ninguna clase social; el franquismo no fue un régimen ni fascista ni totalitario; España tiene una historia normal.

Estas líneas de argumentación explican el que a otras dos instituciones, la Iglesia y la monarquía - de las que me ocupo a continuación-, se las pretenda disociar del franquismo, exonerándolas de toda corresponsabilidad.

La Iglesia católica, que fue desde la proclamación de la República una abanderada del golpe militar, se aprestó a convertirse en la garante del régimen cuan- 
do éste, al término de la segunda guerra mundial, necesitaba con urgencia borrar de la memoria de las democracias occidentales sus orígenes fascistas. La Iglesia católica era -lo había sido desde antes de comenzar la guerra- coherente con el espíritu del tristemente famoso telegrama de Pío XII a Franco, del 31 de marzo de 1939: «Levantando nuestro corazón a Dios, damos sinceras gracias con Su Excelencia por la victoria católica de España». Hay que ver en la cita que sigue la explicación última de las palabras del Papa y de la participación de la Iglesia en la «Cruzada»; es decir, el materialismo del espiritualismo de ese discurso y de esa conducta:

Por fin, la Iglesia española aparecía liberada de los ataques que habían caracterizado al siglo XIX y que culminaron en la legislación laica de la República. La Iglesia aceptó de buen grado el cargo de autoridad legitimadora, que había de presidir a lo largo de las décadas venideras del franquismo. En realidad, la Iglesia y el Estado quedaron tan íntimamente unidas que se creó un modelo de nacional-catolicismo. Franco iba a arriesgar en esta ideología el futuro a largo plazo de su dictadura, preferentemente al falangismo totalitario (Cooper, 1967: 97).

Ferrándiz Alborz recordaba, en 1957, en la revista España Republicana de Buenos Aires, algo que de sabido demasiado a menudo se olvida: "Junto con los intelectuales, se expatrió una multitud de personas más humildes, obreros y labradores, que también representan una merma sensible para la nación». A continuación, añadía que era una grave equivocación dejar de lado este «aspecto del problema» o considerar «fuera de lugar relacionarlo con la cultura literaria, científica, artística». Entre otros motivos, seguía argumentando Ferrándiz Alborz contra tamaño error, porque:

Una cultura no es sólo el libro que se escribe, el cuadro que se pinta, la escultura que se modela, la música que se compone, el fenómeno que se investiga, la clase que se desarrolla. Es también el campo que se ara, la casa que se levanta, el hierro que se forja, el motor que se mueve, etc. [...] En Europa y América son continuos los lamentos -justificados- sobre la situación de los intelectuales españoles, como si ellos fueran toda la cultura española como si la cultura se mantuviera del aire y en el aire, sin una base social, realidad y circunstancia, de la cultura española. Y es esto precisamente lo que dramatiza más aún la situación de la cultura española (Ferrándiz Alborz, 1957).

Nadie discute que la suerte de los intelectuales exiliados y de su producción literaria y artística sea motivo más que merecido de atención y preocupación, pero ello se suele hacer a costa de olvidar que formaban una minoría en el cómputo global del exilio. José Pascual Buxó, en «Las alas de Ícaro», llega a decir:

Una primera manifestación de su neurosis [de Dédalo] fue el menosprecio de aquellos otros que, hijos de modestos canteros que acompañaron a Dédalo en su destierro, como antes lo habían servido ingenuamente en la construcción del primer laberinto, no merecían equiparársele en el nombre ni en las obras (1995: 396).

Anales, 21, 2009, pp. 39-66 
El historiador Manuel Tunón de Lara advirtió hace ya muchos años que no es posible comprender el exilio cultural sin tener presente que constituyó un éxodo de masas. El exilio fue una adversidad compartida por el exiliado cultural y el hombre del pueblo, así de simple y sencillo. Lo cual llevaba a Tunón de Lara, hace ya años, a cuatro «rasgos esenciales» del exilio, de los que destacaré los tres primeros:

1. Se trata de un hecho de masas, multitudinario.

2. Este exilio de 1939, tradicional en nuestra historia de exilios, tiene una nota específica: al convertirse en un asunto de multitudes que abandonan sus raíces porque no tienen opción -es el exilio o la muerte o la privación de libertad- se configura como auténtico destierro.

3. Este exilio se proyecta -con caracteres de permanencia- en muy diversos países, tanto geográfica como cultural y socialmente (1977: 27).

Más recientemente, otros dos historiadores han recordado -lo que parece asimismo haber caído en tierra baldía- que

explicar el exilio a través de la trayectoria de sus personajes relevantes, de su enorme proyección cultural en las Américas [...] es reduccionista, porque desde un punto de vista sociológico fue todo un pueblo el que emigró forzosamente al acabar la guerra civil. Visto desde esta perspectiva la historia del exilio debería abarcar, como quería Gramsci, «a todos los hombres, a tantos hombres como sea posible» (Martínez Leal y Martínez Sáez, 1995: 125).

Las estadísticas del exilio republicano, aunque no son completamente fiables -hay para ello motivos de índole diversa-, son elocuentes. Porque tanto las realizadas por Lois E. Smith, Javier Rubio, Vicente Llorens, o con anterioridad las detalladas en la Memoria de Quintanilla sobre los exiliados que llegaron a México en el Sinaia, la de El Mercurio de Santiago de Chile sobre los 2.000 exiliados del Winnipeg, que fletó Pablo Neruda, o las de España Republicana de Buenos Aires, la más detallada, corroboran, por encima de toda sospecha, que el exilio republicano estuvo compuesto en más de un noventa y ocho por ciento por una ciudadanía de obreros, campesinos y cuadros medios de distintas profesiones. Una de esas fuentes, la más detallada, es -lo acabo de mencionar- la de España Republicana de Buenos Aires:

De los trescientos mil españoles que lograron salvar los Pirineos para no verse sometidos a la indignidad franquista y a su terror, se ha logrado hacer un censo por profesiones, de ciento sesenta mil. He aquí su clasificación:

Obreros agrícolas, 45.918; técnicos de agricultura, 529; avicultores, 110; horticultores, 1.015; vaqueros, 797; panaderos, 9.721; carniceros, 917; fabricantes de conservas, 99; destiladores, 189; marinos, 2.688; pescadores, 1.091; ingenieros, 278; arquitectos, 46; albañiles, 8.590; marmolistas y picapedreros, 924; tipógrafos, 195; peones, 6.938; mecánicos, 5.110; torneros o ajustadores, 2.611; aserradores, 824; soldadores, 364; forjadores, 920; mineros, 2.721; carpinteros, 5.922; metalúrgicos, 3.783; obreros de aviación, 395; de construcciones navales, 293; de caminos de hierro, 413; del automóvil, 714; armeros, 105; de productos químicos, 565; electri- 
cistas, 2.809; especializados en telegrafía sin hilos, 490; conductores de automóviles y mecánicos, 6.524; ferroviarios, 3.034; obreros del cuero y pieles, 705; tejedores, 3.311; de la seda, 63; sombrereros, 235; sastres, 928; zapateros, 1.568; médicos, 533; farmacéuticos, 258; enfermeros, 503; dentistas, 135; ópticos, 41; obreros del libro, 2.440; maestros de escuela, 2.053; intelectuales diversos, 2.378; empleados del comercio, 6.325; empleados de la administración, 3.616; oficiales del ejército, 1.832; de la marina, 310; de aviación, 210; técnicos diversos, 2.572; obreros sin clasificar, 19.338.

Entre estos ciento sesenta mil compatriotas emigrados, hay alrededor de cinco mil intelectuales clasificados así:

Abogados, 400; procuradores, penalistas, notarios y secretarios judiciales, 9; archiveros, bibliotecarios y arqueólogos, 32; arquitectos, 73; artistas y actores, 101; cineastas, 32; compositores de música, 24; decoradores, 1; escultores, 30; dibujantes, 52; grabadores, 4; ceramistas, 2; fotógrafos, 4; pintores, 109; músicos y danzarines, 18; escritores, 221; periodistas, 498; farmacéuticos, 40; funcionarios, 33; ingenieros aeronáuticos, 5; ingenieros de caminos, 19; ingenieros electricistas, 13; ingenieros geógrafos, 4, ingenieros de minas, 10; ingenieros industriales, 198; ingenieros militares, 18; ingenieros de montes, 5; ingenieros navales, 2; ingenieros químicos, 11; ingenieros del sonido, 2; ingenieros textiles, 3; ingenieros mecánicos, 2, y diversos, 56; doctores y licenciados, 45; médicos, 338; practicantes, 45; catedráticos de Universidad, 105; catedráticos de Instituto, 45; otros profesores, 131; profesores de escuelas normales, 146; sacerdotes católicos, 90; técnicos aparejadores, 20; comercio, banca y estadística, 105; meteorólogos, 2; peritos agrícolas, 65; peritos industriales, de montes y químicos, 180; peritos textiles, 5; pilotos de mar, 25; telegrafistas y radiotelegrafistas, 14; topógrafos, 39; veterinarios, 6; maestros, 1.301; estudiantes de diversas facultades y especialidades, 522 .

Podemos afirmar que entre estos intelectuales están nuestros más altos poetas, músicos más inspirados, nuestros mejores médicos, nuestros mejores profesores; nuestros políticos más reputados.

Y entre los trabajadores -todo lo bueno y lo mejor- hay labriegos andaluces que le sacan zumo al relleno; tipógrafos de la estirpe de Ibarra, hortelanos de Valencia y de Murcia, ajustadores de Eibar, plateros de Córdoba, oríferes de Toledo, panaderos y albañiles de Madrid, ganaderos de Extremadura, electricistas de los grandes saltos modernos, mecánicos, viñadores, olivareros, mecánicos de aviación...

Estos son, para orgullo nuestro, la «horda roja» de que aullaban en los días del éxodo los miserables hijos de Caín que traicionaron a España y continúan ensangrentándola todavía («La "horda roja”», 1941).

Los refugiados fueron, desde un primer momento, un problema humano y económico para Francia, por lo que las autoridades francesas, que tomaron la decisión de internar a miles de españoles en campos de concentración, buscaron países que estuvieran dispuestos a acoger a cuantos fuera posible. Se pretendía así minimizar el problema que para ellos representaba un éxodo de tales proporciones. Los refugiados, por su parte, estaban dispuestos a abandonar cuanto antes el país porque, por un lado, el trato les resultaba vejatorio y, por otro, se avecinaba el estallido de la segunda guerra mundial y sus vidas, estando internados en territorio francés, corrían peligro.

Anales, 21, 2009, pp. 39-66 
Los países latinoamericanos que acogieron a los exiliados republicanos tenían sus propias políticas migratorias, que iban dirigidas prioritariamente a la captación de contingentes pertenecientes a las clases trabajadoras. Los representantes del Gobierno mexicano en Francia actuaron, en la mayor parte de los casos, según las directrices que recibían de su país. En el Cuarto Informe de Gobierno del presidente Cárdenas, fechado el 1 de septiembre de 1938, se anunció oficialmente que habría próximamente una reglamentación de la emigración de españoles y de otras nacionalidades. Se anunciaba, en ese informe, que tendrían prioridad los emigrantes que se dedicaran a la agricultura, la industria o el comercio de exportación. El Consejo Ejecutivo de Migración de México elaboró de manera más concreta, en los primeros meses de 1939, una serie de disposiciones especiales por las que se favorecía la emigración de los refugiados españoles en Francia, que incidían en lo ya establecido en el Cuarto Informe de 1938.

Lo mismo cabe decir de Chile. Pablo Neruda manifestó, en diciembre de 1939 -poco después de haber organizado la expedición de los «2.000 del Winnipeg»-que «su labor en Francia se hizo de acuerdo con las órdenes recibidas de su jefe el Ministro de Relaciones Exteriores»; y añadía:

Mi país necesitaba capacidades calificadas, hombres de voluntad creadora. Necesi-

tábamos especialistas. El mar chileno me había pedido pescadores. Las minas me pedían ingenieros. Los campos, tractoristas. Los primeros motores Diesel me habían encargado mecánicos de precisión (Neruda, 1974: 198).

Joaquín Edwards Bello dejaba constancia, en un artículo de septiembre de 1939, de que, en efecto, Neruda se había ajustado a las instrucciones de su gobierno, o lo que es lo mismo, a lo que necesitaba su país:

Llegaron a Chile dos mil emigrantes españoles, la mayoría de ellos obreros. ¡Bienvenidos! Chile es un espacio sin pueblo. La primera impresión de los campos chilenos es de anemia, de ausencia de humanidad. Falta gente, mucha gente. Pero al pueblo chileno le desagrada el obrero extranjero, competidor (Edwards Bello, 1939).

Guerra, represión y exilio, historia protagonizada y sufrida en carne viva por miles y miles de republicanos, heridas abiertas de una colectividad que acaso solamente puedan cicatrizar reinventando un futuro en el que las historias perdidas o mal conocidas -la fosa, realidad y metáfora- de las víctimas sean la urdimbre para hilvanar una trama individual y colectiva, una historia individual y colectiva.

Los materiales de esa reconstrucción se remontan al pasado, a cuanto estaba, sigue estando, reducido a un cúmulo desperdigado de dolor y memoria acallada.

De dolor y memoria acallada que reclama la dignidad del recuerdo.

La represión y el exilio son una memoria acallada que ha de emprender un regreso al espacio-tiempo del ayer, porque es justo y lo necesita este hoy 
de cada día, y desde él narrar, contar, dar testimonio y ser eso, memoria viva. Un regreso tal se ha de emprender a pesar de la inevitable erosión del tiempo en las cosas, y en la memoria también. Una erosión que no para de acosar, de hostigar, de desgastar, de ir poco a poco desdibujando, casi borrando, casi haciendo ininteligible, irreconocible los muñones del ayer. Si se desdibujara y se borrara, si se volviera irreconocible del todo el pasado, el tiempo de la infamia, una aséptica, grisácea paz -como impuesta por un conjuro o pacto de milicos y civiles- recubriría, o está recubriendo ya, este ignominioso espacio de este hoy.

Hayden White, en «El valor de la narrativa en la representación de la realidad», saca a colación que Hegel, en Lecciones sobre filosofía de la historia, planteaba que ni la «historicidad» ni la «narratividad» son posibles, que ni una ni otra -por otra parte, tan emparentadas, pues las anima por igual el mismo propósito de configurar la experiencia humana- son posibles, sin la noción del «sujeto legal», sujeto a quien corresponde ser medio y tema de la narrativa histórica. Hecha esa relación entre legalidad, historicidad y narratividad, no ha de sorprender -continúa diciendo Hayden White- la frecuencia con la que la narratividad, bien ficticia o real, presupone la existencia de un sistema legal a favor del cual o en su contra pudiera escribirse, narrar (White, 1992: 27-28). Y remontándose a los anales medievales señala además que el impulso a narrar los conflictos y efemérides estaba ya entonces vinculado al deseo por parte del narrador de representar a una autoridad, cuya legitimidad dependía de la clarificación, en la dirección de quien ostentaba el poder, de los hechos históricos (El contenido de la forma, 1992: 34-35).

En el pensamiento del sofista Protágoras, conservado de manera fragmentaria, encontramos razonamientos como éste: «El hombre es la medida de todas las cosas, de las que son en cuanto que son y de las que no son en cuanto que no son» (Barrio Gutiérrez, 1984: 18). Es decir, para Protágoras «cada hombre individualmente considerado, sería el determinante existencial de lo real» (Barrio Gutiérrez, 1984: 21). Pero como el individuo vive en una comunidad -la pólis-, es parte y miembro del Estado. Pero, así las cosas, ¿quién legisla, entonces, el individuo o el Estado (pólis)? ¿Puede existir un Estado (pólis) con todas las representaciones de la realidad que tenga cada uno de los individuos? De la necesidad utilitarista nace la propuesta de Protágoras de que la puesta en valor de las sensaciones y de percepciones de la realidad «no es verificada por el sujeto individual, sino que le es impuesta por el grupo social, por la sociedad en que vive. Es la sociedad la que estima lo valioso y lo antivalioso, y el hombre, moldeado por dicha sociedad acata las valoraciones de ésta» (Barrio Gutiérrez, 1984: 22). 
O dicho con otras palabras, también de Protágoras: «Pues lo que a cada Estado (pólis) le parece justo y bello, efectivamente lo es para él [Estado/pólis], mientras que tenga el poder de legislar» (Barrio Gutiérrez, 1984: 21).

Por un lado, por tanto, se proclama el principio de individualidad y, por otro, se niega ese principio, al ser sometido a una entidad superior que pide sumisión, obediencia, dejación de unos derechos naturales. Una dejación que abre no pocas interrogantes: ¿Son todas las leyes iguales? ¿Tienen el mismo valor las que nacen de una voluntad popular torcida por el miedo como las que son expresión del deseo expresado en libertad? ¿Puede expresar libremente sus deseos un pueblo al que se le arrebató el deseo y se le sometió a una violentísima guerra y a una larga y tortuosa dictadura? ¿Quién modificó la naturaleza de las cosas, el voto o el poder absoluto? ¿Legisló enmascarada la fuerza bruta? ¿Hicieron, pueden hacer tales leyes -cuántas sombras se ciernen sobre la Transición...- justo lo injusto?

Cada interrogante, cada pregunta -cada sombra- encierra un fragmento, es una parte del todo, y está, a la vez, llena de interrogantes, de preguntas, de sombras... Pero hay que preguntar y responder, construir y reconstruir. Meterse en el laberinto y buscar una salida. $\mathrm{O}$, si no hay más remedio, perderse en él. Pero buscando, buscando una salida... al laberinto.

¿Puede recuperar el ciudadano su condición de sujeto legal? ¿Puede enfrentarse el súbdito al Estado (pólis) cuando éste ha doblegado, ha secuestrado su deseo? Quizás, como sugiere Hayden White, sea la propia realidad la que dictamine que, en efecto, es posible y conveniente -deseable- que así sea. Porque la realidad pide ser narrada, y esa exigencia confiere al narrador $-\mathrm{y}$ a ella misma, por la misma lógica- una autoridad (White, 1992: 34-36).

El individuo -el súbdito- recupera así su condición de sujeto, requisito indispensable para que el Estado (pólis) recupere a su vez su legitimidad, su derecho a decretar según el deseo del pueblo.

Esa condición recuperada de sujeto devuelve la historia a los predios de la realidad real, que permite el que pueda aflorar el discurso de lo real. Discurso que acaba convirtiéndose él mismo en objeto de deseo en la medida que hace deseable lo real. Para lo cual ha de presentarse lo real con la coherencia formal de los acontecimientos históricos. De este modo, como dice Frank Kermode en The sense of an ending, el "peso de la significación» de los acontecimientos contados se «proyecta» a un futuro que va algo más allá del inmediato presente, un futuro cargado de juicio moral y de castigo para los malvados (White, 1992: 36-37).

Pero, claro, ¿cómo se podrá construir o reconstruir el futuro si la ciudadanía se desentiende, o la obligan a desentenderse, de su pasado? Porque de, por una u otra vía, ser así, ¿a quién podrá interesar realmente hoy en día el debate sobre 
la democracia entre Protágoras y Cicerón, el discurso histórico de Hayden White, el juicio moral de Frank Kermode...? ¿A quién le importaría hoy en España descubrir o reconocer que se está, al menos potencialmente, en un laberinto? Más aún, ¿qué es hoy España? ¿Es una historia de fragmentos entrelazados, de hilos narrativos que se engarzan y cuentan una narración, que relatan la historia de un empeño compartido o es «a tale/ told by an idiot,/ full of sound and fury/ signifying nothing» (Macbeth, V,v). Mefistófeles, en el Fausto de Goethe, había declarado solemnemente: "Gewöhnlich glaubt der Mensch, wenn er nur Worte hört / Es müsse sich dabei doch auch was denken lassen» (Goethe, 2007: 83).

Los grandes conceptos, los grandes principios no deberían tener valor de trueque. Porque no son en absoluto abstracciones sin sentido en el mercado de valores de la Bolsa, o en el de los valores de la Ética. Como ha escrito hace unos años, con cierta inevitable amargura Nicola Chiaramonte: «Bad money drives out good money. And useful lies corrode useless truths, retiring or falsifying them, for they do not help orient one in the modern situation, succeed in it, or even adjust to it» (Chiaramonte, 1986: 138).

Los que vivieron la represión en el interior, fueron encarcelados, vejados, fusilados, y los que se convirtieron en refugiados políticos, fueron acorralados en zonas fronterizas, presos en campos de concentración, náufragos todos en todas partes, dentro y fuera de España, de la historia, se agarraron, era una salida a su alcance y muchos echaron mano de ella aunque solamente fuera en su fuero interno, a la tabla de salvación del recuerdo, de la rememoración del pasado. Cada uno era un fragmento real o en potencia de una totalidad quebrada, desgajada. Su historia, que es la historia de un tiempo infame de España, tiene ese agarradero de la memoria, que debe hacer posible recuperar aquellos sueños, aquel pasado.

Pero la palabra, la verbalización de la experiencia, el acto de narrar, si bien tienen la potencia de ser un antídoto contra la desmemoria y permiten seguir resistiendo, aferrarse al mundo, a la vida, y hasta funcionan como mecanismos, conscientes o inconscientes, de autoafirmación, y también hasta ponen a salvo la identidad de quienes son considerados, fuera o dentro de su país, proscritos, no por ello dejan de ser un artificioso sucedáneo.

Porque el represaliado, el exiliado, el emigrante, las víctimas de aquel tiempo de infamia, experimentan en carne propia la terrible realidad de que la palabra, el acto de narrar, de contar, nunca puede sustituir a los actos, a la acción, ni que la dolorida memoria del pasado -demasiado a menudo refugio de la impotencia-consiga reemplazar el siempre fulgurante deseo de formar parte integrante y de pleno derecho de una colectividad. De ser, en suma, un fragmento integrado en una totalidad. 
No hay, pues, salida posible al oprobio. Esa condena, cuando busca una salida en la palabra, que es a lo sumo un refugio, no libera de las redes del ayer, del laberinto del pasado. Porque todos, ellos y nosotros, queremos sobre y por encima de todo ser, día a día, acto, realidad o expectación de conseguir eso, ser acto, realidad, en un tiempo presente que sea siempre atisbo de futuro, apertura al futuro. Queremos, en suma, que nuestros deseos -individuales o colectivos, privados o públicos- se cumplan en esta hora de hoy y en la de mañana. Y en la de otros muchos mañanas. No nos conformamos con unos eslabones sueltos, queremos toda la cadena, con los eslabones uno tras otro, en continuidad y con la idea del conjunto. De ahí que la cadena escindida, sin sucesión de continuidad no sirva, pues es una imagen de lo roto, de lo desgarrado, de la frustración, del fracaso.

Estamos hechos de la estofa del ayer, pero queremos seguir siendo, paso a paso, tramo a tramo, un proyecto de presente y de futuro. Queremos tener un objetivo, una finalidad, algún sentido, tal esa zigzagueante y temblorosa flecha, a la que hace referencia Aristóteles en Etica Nicomáquea (I, II):

Si existe, pues, algún sentido (télos) de nuestros actos que queramos por sí mismo y lo demás por él, y no elegimos todo por otra cosa -porque así se seguirá hasta el infinito, de suerte que el deseo sería vacío y vano-, es evidente que ese sentido y plenitud será lo bueno y lo más excelente. Y así, el saber esto, ¿no tendrá gran influencia en nuestra vida y como arqueros que saben también a dónde dirigen sus flechas no dirigiremos las nuestras hacia donde debemos.

Como señala Edward Said, en «The mind of Winter», añadiendo a la condición de exiliado un ingrediente político que siempre está inherente en esa condición que comparten, aunque haya diferencias, con el represaliado que no ha podido o querido abandonar su país:

Exiles are cut off from their roots, their land, their past. They generally do not have armies, or states, though they are often in search of these institutions. This search can lead exiles to reconstitute their broken lives in narrative form, usually by choosing to see themselves as part of a triumphant ideology or a restored people. Such a story is designed to reassemble an exile's broken history into a new whole (Said, 1984: 51).

Volvemos por tanto, a la cuestión, aquí constantemente reiterada, de la estructura fragmentaria, rota -de ahí el título, Antología rota, del poemario de León Felipe- de la obra literaria de aquella España de infamia. Pero no se trata solamente de la estructura fragmentaria, rota, de la obra literaria, sino además -y esto es aún más importante- de la condición fragmentaria, rota, de la vida de las víctimas de aquella España.

El énfasis, en todo lo que atañe a aquel tiempo, a aquella España, está en lo plural, en la pluralidad de voces. De voces, de dentro y de fuera, que se buscan, 
que se necesitan. Y no podían -ni pueden aún- encontrarse. Era -y sigue siendo- parte del castigo, de la condena.

Acaso convenga recordar de pasada, como entre paréntesis, que la escritura de la historia como la escritura literaria tienen, estructuralmente, relaciones estrechas. Lo cual hoy empieza a ser aceptado hasta por los historiadores, siempre reacios a aceptar que hacer historia es una manera de narrar.

La estructura fragmentaria de la narración histórica y de la narración literaria ha abierto el debate -en clave posmoderna- de si estamos inmersos en un mundo de fragmentos, de puntos de vista inconexos y dispersos y, por ello, sin posibilidad de constituir unidades o totalidades superiores de sentido. Un argumento que rechazamos quienes pensamos que la estructura fragmentaria no implica esa imposibilidad. Aceptar tal premisa quebranta el principio, al que ha de aspirar toda narración -histórica o literaria-, de coherencia y de sentido. Y es que los fragmentos no existen -la tesis posmoderna- para perdernos en el caos de lo disperso sino para buscar, relacionándolos entre sí, engarzándolos unos en otros, estructuras significativas. Estructuras que están o pueden estar construidas con materiales dispersos y hasta caóticos, pero, a pesar de ello -o por ello- pueden terminar cristalizando, componiendo unidades de sentido y finalmente de acción. Gilles Deleuze, en Proust y los signos, presenta estos extremos con la siguiente disyuntiva: «Cuando una parte vale por sí misma, cuando un fragmento habla en sí mismo, cuando un signo se alza [...] puede ser bien porque permite adivinar el todo del que está extraído o bien porque no existe totalidad en la que pueda entrar» (Deleuze, 1970: 117).

Pero si no existe totalidad en la que entrar, iese fragmento no será ya por fuerza una totalidad? Pero, como sea, si uno de esos «fragmentos habla en sí mismo» $\mathrm{y}$ «permite adivinar el todo del que está extraído», eso ya es mucho, mucho más de lo que a menudo se admite en determinados círculos posmodernos.

Roland Barthes ha señalado que hay una ilación entre los hechos objeto de la historia, o sea el referente sobre el que se basa el discurso histórico, y el acto de narrar, de articular, de verbalizar el referente en un discurso. Según Roland Barthes:

Dans le discours historique de notre civilisation, le processus de signification vise toujours à «remplir» le sens de l'Histoire: l'historien est celui qui ressemble moins des faits que de signifiants et les relate, c'est-à-dire les organise aux fins d'établir un sens positif et combler le vide de la pure série (Barthes, 1982: 19).

Norman Malcolm argumenta, por su parte, en «Memory and representation», que recordar es una forma de pensar, y que en todo pensamiento debe haber algo (una idea, una imagen, una proposición) que es el contenido del pensamiento. Norman Malcolm sigue diciendo en su artículo que para Wittgenstein, 
en Tractatus logico-philosophicus, una proposición es «as a picture of reality», y que el hecho de que «the picture elements are related in a certain way is the structure of the picture» (Malcolm, 1970: 62-64).

Esto es lo que viene a decir el propio Max Aub en uno de los apuntes de «Cuaderno Verde» de Jusep Torres Campalans: «Pintura en libertad sólo ordenada por el tamaño del cuadro». Claro, el cuadro sirve de marco, hace inevitable que la totalidad pintada tenga unos límites. Toda estructura los tiene. Pero esos límites no niegan la idea de estructura, sino que la hacen posible. Posible y necesaria. Sin salirnos de la pintura, pongamos del revés lo dicho hasta aquí. Veamos lo dicho, en fin, de otra manera.

John Berger, en Ways of seeing, el guión de una serie televisiva sobre pintura, argumenta que cuando una cámara reproduce imágenes, es decir fragmentos de un cuadro, ese cuadro, a través del ojo de la cámara, se convierte inevitablemente en un argumento, en una trama. Para Berger «a film unfolds in time and painting does not. In a film the way one image follows another, their succession, constructs an argument wich becomes irreversible» (Berger, 1979, 29). Y por otra, las palabras que comentan el cuadro mientras la cámara presenta imágenes necesariamente fragmentarias del cuadro -necesariamente fragmentarias como los comentarios que las acompañan en el discurrir temporal de la cámara y de la voz que las narra, imágenes y palabras acuñando una sintaxis de colores y de sonidos, buscando un sentido, una comprensión-, quitan al cuadro su significación independiente.

Las palabras del comentarista -oraciones, párrafos, parcialidades discursivas que crean una totalidad cuando ponen punto final a la lectura del cuadro- adquieren como las imágenes filmadas -partes que va seleccionando la cámarauna autoridad propia, autoridad ligada a la no menos autoritaria organización de las imágenes filmadas. Pero esa posición de dominio más que una conquista es una carga, porque el enunciante está condenado a la imposibilidad de verbalizar, de apropiarse verbalmente en su totalidad de los significados estáticos, mudos, anclados en el pasado, del referente.

Con todo, esa imposibilidad no supone que haya que rechazar la idea de estructura ni tampoco que esté ausente una meta -la flecha de Aristóteles en la cita de la Etica Nicomáquea (I, II)-, que sea imposible tener una dirección, la determinación de encontrar y transmitir un sentido.

Si es cierto, como afirma John Berger, ahora en And our faces, my heart, brief as photos, que «to emigrate is always to dismantle the center of the world, and so to move into a lost, disoriented one of fragments» (Berger, 1984: 57), no es menos cierto -me permito también aventurar- que en nuestro proceso migratorio -nacer es el comienzo del exilio, la pérdida de la seguridad, del no-tiempo, 
abandonar la trinchera del espacio uterino... nacer es, en suma, salir a los caminos del mundo abocados a un lento pero irremisible ir muriendo, o lo que es lo mismo ser pasado, memoria, olvido...-, pues bien, en ese proceso migratorio, perdido el centro y enfrentados a un mundo de fragmentos, buscamos la utopía de unir los fragmentos, nos empeñamos en recomponer ese rompecabezas, inventando tramas que tengan, como la vida, un comienzo, un medio y un final. Y es que nuestras vidas, como toda suerte de narraciones, han de tener acción y sentido. Según dice Wolf Singer, en la revista alemana Theaterschrift:

Das Gehirn versucht, was es wahrnimmt, in ein Ordnungsprinzip zu bringen. Es ist nicht zufrieden damit, etwas als unverständlich anzuerkennen, vor allem dann nicht, wenn es als Kunst daherkommt. Der Rezipient weiß, daß er daraus irgendetwas machen soll. Davon profitiert der Künstler, er spielt mit dem Vorwissen der Rezipienten und dessen Suche nach Sinn und Kohärenz (Singer, 1994: 30).

Las fotografías contribuyen a cimentar esta argumentación. Podríamos recordar, entre otros muchos, los libros de Frank Capa, de Roland Barthes o de Susan Sontag sobre teoría de la fotografía, o algunas novelas, como Escenas de cine mudo de Julio Llamazares. John Berger, en Another way of telling, señala que en cada fotografía se detiene el tiempo, cada fotografía recoge, cristaliza, inmoviliza un instante del pasado -algo que ha existido y no volverá a existir-. Las fotografías -así se graban también los recuerdos en la memoria-, «isolates the appearances of a disconnected instant» (Berger, 1995: 89). Lo cual implica la idea de fragmento. Pero también las ideas de ilación, de ensamblaje, de totalidad. Porque así lo requiere la coherencia, la necesidad de encontrar a la experiencia un sentido -o sentidos-. Como concluye John Berger: «In life, meaning is not instantaneous. Meaning is discovered in what connects, and cannot exist without development. Without a story, without an unfolding, there is no meaning. Facts, information, do not in themselves constitute meaning» (Berger, 1995: 89).

Una constatación de ello la ofrece también el libro de Julio Llamazares, Escenas de cine mudo, donde un álbum de fotografías - que tiene mucho de implied narrative, pues las fotos están ordenadas temporalmente, conteniendo fragmentos de un devenir, de una sucesión- piden palabras, piden una interpretación. Que es la función principal, esencial, de las palabras: narrar, interpretar, desvelar sentido. Nunca son solamente sonidos, música. Por otra parte, la música también narra, tampoco se libra de transmitir, de comunicar sentido.

Hay que ver las fotos como fragmentos del pasado. Las fotos -o las fosas-, lo que en ellas hay, aparece en un contexto, siempre existe una interrelación en cuanto en ellas ha recogido el ojo de la cámara. Cada una de las fotos que uno va tomando y reuniendo, colocadas en un orden cronológico o temático, o sin 
orden alguno, son materiales -signos, al fin, como los restos de las víctimas que se conservan en las fosas- para reconstruir una historia, una parte del pasado que remite a unidades significativas superiores. Son, en suma, una narración en potencia. Simplemente, necesitan, como las imágenes del cuadro a que hacía referencia John Berger, en Ways of seeing, unos ojos que las descubran, que las vuelven a mirar y les devuelven vida, un sentido.

Las fotografías dan a las palabras una prueba irrefutable, son una constatación. Claro es que todo se puede fotografiar de distintas maneras como todo se puede ver/contar/interpretar de formas diversas, incluso encontradas. Pero la realidad, lo que fotografía la cámara, lo que el ojo de la cámara selecciona -lo cual ya es una manera de narrar-, tiene una base, una existencia real. A menudo la fotografía suele recoger más contenido, más realidad que el fotógrafo es en un primer momento -como en Blow-up, de Antonioni/Cortázar-capaz de ver o adivinar. Y es que la realidad es una fuente inagotable de sentido, su capacidad de producir sentido nunca se acaba, nunca. No se trata, por tanto, de poner el énfasis en la naturaleza plural pero inconexa de los discursos, lo cual implica la impotencia o la inutilidad discursiva. Pluralidad, sí; pero conexión también. Y sobre todo hay que apostar por la noción de proceso, de una sucesión de lecturas, de discursos, que van progresivamente -a veces incluso con retrocesosapropiándose de cotas, cada vez mayores, de sentido.

Algo que también corrobora Cézanne en estas observaciones sobre el arte de pintar: «Objects interpenetrate each other. They never cease to live. Imperceptibly they spread intimate reflections around them» (Berger, 1995: 113), que ha comentado así John Berger, en Another way of telling, donde reproduce la anterior cita de Cézanne: «The sight of any single thing or event entrains the sight of other things and events. To recognise an appearance requires the memory of other appearances. [...] As soon as we say that appearances coher this coherence proposes a unity not unlike that of language» (Berger, 1995: 113-114).

Auggie comparte, en Smoke de Paul Auster, con el escritor Paul que es asiduo consumidor de cigarrillos de siempre la misma marca, su diario secreto de fotografías hechas cada día desde el mismo ángulo y a la misma hora. Cada fotografía es una variante de lo igual pero inevitablemente distinto:

Más de cuatro mil fotografias del mismo sitio. La esquina de la calle 3 con la Séptima Avenida a las ocho de la mañana. Cuatro mil días seguidos haga el tiempo que haga. [...] Todas las mañanas en el mismo sitio a la misma hora. [...] Sólo una pequeña parte del mundo, pero también allí pasan cosas, igual que en cualquier otro sitio. Es un documento de mi pequeño lugar. [...] Son todas iguales, pero cada una es diferente de todas las demás. Tienes mañanas luminosas y mañanas sombrías. Tienes luz de verano y luz de otoño. Tienes días laborables y fines de semana. Tienes gente con abrigo y botas impermeables y gente con pantalones cortos y camiseta. A veces son las mismas personas, otras veces son diferentes. Y a veces las personas diferentes se 
convierten en las mismas y las mismas desaparecen. La tierra da vueltas alrededor del sol y cada día la luz del sol da en la tierra en un ángulo diferente (Auster, 1995: 54-57).

En las fotografías, al igual que en los cuadros, el movimiento -y el tiempoestá detenido. Pero existe irremediablemente una conexión con la realidad que reproducen. Y la realidad nunca es una abstracción, ni tampoco es como en la fotografía o en el cuadro, una parcialidad aislada, autónoma del todo. Su naturaleza es ser un todo, una unidad, con apariencia plural y múltiple, diversa, para quien la contempla y la narra, pero es, al fin, una unidad.

En cada foto, en cada cuadro, hay miles de posibles historias y a la vez una sola historia. No siempre se comprende que contar las mil posibles historias está más cerca de nuestra realidad humana que el contar esa sola historia, lo cual no está a nuestro alcance. Porque nuestra naturaleza, no la de la realidad, está condicionada por el lastre de la subjetividad, de la parcialidad de nuestra mirada, de nuestra comprensión/narración siempre incompleta. Anuncia el día su inminente estallido. Avanza en el horizonte un tímido pero encendido grana que se va tornando violeta azul claro, amarillo pajizo intenso añil... El cielo, encapotado, impone un gris plomizo que borra esta incipiente, tímida auroral policromía. Unas pocas nubes ligera, tímidamente rojizas resisten con bravura. El bosquecillo de chopos, en este día otoñal, cobija solitarias tórtolas abandonadas a la espera y al frío. El tiempo detenido, replegado sobre sí mismo, ofrece la ilusión de una tregua que la naturaleza se resiste a cumplir. Mas el tiempo de mi contemplación, este convertir el paisaje en lenguaje este tiempo sobre el tiempo sólo es ya artificio en doblete, falsa falsedad o apañado idilio en donde se cruzan y entrecruzan la subjetividad y la intersubjetividad.

Somos individualidades - unidades- condenadas a ser parte de un todo, de una colectividad, de un conjunto, que nos forja y nos condiciona, hasta cuando nos rebelamos, hasta cuando queremos, ilusoria, puerilmente afirmarnos distintos, únicos. Una especie aparte.

Así, cuando observo con detenimiento la fotografía, o fotomontaje, de Genovés que aparece en la cubierta de La larga marcha de Rafael Chirbes (en la edición española), me perturba que todos corran en una misma dirección. Porque esa marcha la ha producido una detonación, que metaforiza la mano de hierro que amedrenta a la ciudadanía -la dictadura de Franco, evidentemente-, y todos corren, corren contando una misma historia, la historia de esa mano de hierro. Sin embargo, en La larga marcha, aparece una pluralidad de individuos cada uno con una historia diferente, diferente pero condicionada, entrelazada, interconectada, por el discurso de la fuerza, por el discurso autoritario del dictador. La fotografía, o fotomontaje, de Genovés alcanza su pleno sentido con 
la lectura de la novela. La larga marcha nunca tiene la unidimensionalidad que presenta la foto porque, como en el Laberinto mágico de Max Aub, el hombre está condicionado por una superestructura histórica, pero es, sigue siendo un hombre. Sujeto, y a veces víctima; pero siempre sujeto. Y nadie, ni siquiera en esa misma situación límite que compartieron los exilios del exterior y/o del interior durante la dictadura de Franco, puede impedir a cada una de las víctimas tener su personal lectura/narración de la historia y de su propia historia. Narrar, para lo cual hay que tener memoria, dos capacidades que si las ejerce, hacen irreducible al hombre, superior a la más cruenta e inhumana dictadura. Cuando el hombre renuncia a esa doble capacidad, suele ocurrir irónicamente en los tiempos de democracia formal, es porque ha caído en las redes de otra dictadura, más sutil e imperceptible quizá. Pero dictadura, al cabo.

Así las cosas, al que habita fuera de su espacio natural, sea represaliado o exiliado, si no cae en la autocomplacencia personal o en la mitologización de su pasado, en el discurso uniformador, monológico, le espera una función -aunque sus efectos se noten solamente a largo plazo- decisiva.

Pero, como fuere, la experiencia individual es inseparable -como ha demostrado Maurice Halbwachs- de la colectiva. Todo propósito de allegar las experiencias personales remite necesariamente a referentes históricos. El mundo privado es otra de las muchas quimeras que se esfuman. Y, sin embargo, la ilación discursiva de lo disperso y fragmentario se apoya en la lastimada, siempre única y personal, siempre intransferible, expresión personal, al reducto íntimo. La memoria o el recuerdo, por mor de la palabra, de la lengua, permite instrumentalizar el proceso de recuperación, de cura. La memoria del pasado y su verbalización son antídotos contra el abandono y la renuncia, contra la aceptación del fracaso. También -acaso sobre todo- contra el desorden impuesto.

La idea de fragmentación, de desorden y caos, también de mutilación y pérdi$\mathrm{da}$, que arrostra todo represaliado y exiliado -todo no integrado en el statu quo-, se compensa, en resumidas cuentas, con la obsesiva necesidad de recuperar el equilibrio desvanecido. Irrumpe así una tensa dialéctica que apunta a la reconstrucción de cuanto se daba por seguro y, como tal, confería una suerte de protección contra lo incierto y lo huidizo, contra lo que, a la postre, define a la existencia.

Rememorar, o sea narrar, es lo que hace un sobreviviente de un campo de concentración nazi cuando cuenta sus experiencias sin pretensiones de ser propiamente un narrador, como es el caso de Jorge Semprún en La memoria o la vida o como cuando un historiador de la escuela que sea escribe un libro repleto de referencias bibliográficas -rehúso por coherencia emplear el término libro científico, no creo que la Historia sea una ciencia exacta- sobre los campos de exterminio. Rememora, esto es, narra por igual quien cuenta el cuento de que 
la transición española es el modelo más acabado de transición o quien quiere demostrar lo contrario.

En definitiva, el acto de rememorar -de narrar- es siempre crear tramas -a veces, intrigas- sobre el pasado que tienen por mediación el presente, la necesidad desde la siempre incierta hora más actual de esclarecer el inabarcable y a menudo desconcertante y escurridizo tiempo pretérito. Continuamente, la voz apremiante y oscura del pasado nos llama, nos urge, nos apremia, necesita, sumida en el desamparo del silencio y el olvido, que narremos y desentrañemos su acabada existencia y a pesar de ello su perdurable sentido. Gabrielle Spiegel escribía en 1993: "¿Qué es el pasado sino a la vez una existencia, ahora silenciada, existente únicamente como signo y en condición de tal atrayendo hacia sí cadenas de interpretaciones conflictivas que revolotean sobre su presencia ausente y compiten por la posesión de las reliquias, pretendiendo inscribir trazos de significado sobre los cuerpos de los muertos?»

Pero esa requisitoria se da en estos términos porque el pasado está incrustado en nuestra psique, forma parte de nosotros, y la querencia del pasado a ser narrado es fundamentalmente una necesidad del pasado en la medida que nosotros somos ese pasado. Si no escrutamos y atendemos ese mandato, no hay liberación, no hay cura. Con todo, esa posibilidad de liberación y cura, que difícilmente jamás se producirá en términos absolutos -pongo en la misma balanza al psicoanálisis y a la narración siguiendo la tesis de Peter Brooks en su libro Psychoanalysis and storytelling-, necesita un rito participativo, un continuo proceso dialéctico y dialógico.

«The status of truth is an endless text», dice Peter Brooks en Psychoanalysis and storytelling (1994: 15). Es decir, toda narración lleva en sí el signo de la parcialidad; o está, si se prefiere, sujeta a la pluralidad y a la ambigüedad. Pero, además, la idea de «an endless text» sugiere la noción de movimiento, de progreso, de avance. Se mire como se mire, hay una incompatibilidad, por tanto, entre el «status of truth» y el discurso épico -coloco el nacionalismo en esta categoría-, pues tal discurso ni acepta la parcialidad, ni la ambigüedad ni las nociones de movimiento, progreso y avance.

La memoria de nuestros espacios nativos invita, cuando todo se hunde o parece peligrar, a buscar refugio. María Zambrano, en un artículo de 1933, «Nostalgia de la tierra», decía: «Cuando todo ha fallado, cuando todas aquellas realidades firmes que sostenían su vida [la vida del hombre], han sido disueltas en su conciencia, se han convertido en "estados de alma", la nostalgia de la tierra le avisa de que aún existe algo que no se niega a sostenerle» (Zambrano, 1933).

Además, los lugares de la memoria -para utilizar la expresión de Pierre Nora- remiten a un tiempo vivido. Así espacio y tiempo son los dos grandes 
polos en torno a los cuales gira nuestro pasado y nuestro proyecto de futuro. Emilio Lledó dice en Memoria de la ética:

Todo ser es [...] una «realización», un ens histórico. Este carácter de ente quiere decir que está siendo, que su ser es un estar, y que estar no es la estructura ideal sustentada en un posible cielo teórico, inalterable y total. El estar no es meramente la indicación topológica que delimita un ente o un objeto en un lugar (topos) concreto del espacio, sino en el inestable circuito del tiempo (Lledó, 1994: 24).

Esta superposición temporal -posibilitadora de lecturas del pasado-, que busca un equilibrio en un tiempo marcado por la inestabilidad, no la detenta en exclusiva la escritura novelesca, porque tanto en la novela como en la escritura histórica -es decir, la escritura de los historiadores-, en ambos casos por igual, hay un juego de espejos, de miradas.

Por un lado, está quien observa desde el siempre fluctuante presente y, por otro, está el ayer, lo ya sucedido, sin voz ni palabra, objeto sumiso de una interminable lectura/escritura.

Si el pasado es siempre visto desde la atalaya del presente y acaso por ello está condenado a ser constantemente objeto de interpretación, el presente, como la escritura, acaba siendo una mediación. Como tal mediación, la escritura -novelesca o histórica-, vehiculiza la aspiración de apropiarse de unos referentes teóricamente objetivables que el hoy, imposibilitado de regresar al ayer, tiende a desvirtuar/ficcionalizar. Así, la praxis de la ficción novelesca acaba convirtiéndose, incluso cuando hace gala de una declarada adscripción al método positivista o científico-experimental, en la paradigmática constatación de que nunca se podrá del todo hacer coincidir lo acontecido con su transposición literaria. El escritor siempre traduce. Y traducir, ya se sabe, es un oficio, aun cuando se tengan las mejores intenciones, falsario.

Lo mismo cabe decir del acto de leer. Porque toda lectura es en sí una manera de traducir, de poner en nuestro lenguaje propio - de rescribir, en suma- la realidad. Mirar el objeto real, o pensar el objeto aún no real -una entelequia-, o ansiar el objeto ausente -real o no real-... son por igual maneras de leer, de rescribir lo que está ahí como una realidad o como una carencia. Tal ocurre con el proceso de recordar.

Todos estos discursos -o sea, todos los discursos- que estoy relacionando con el deseo, voluntario o involuntario- de sacar lecciones del pasado, de torcer en una determinada dirección el curso de los acontecimientos presentes, con la ayuda de las lecciones que ofrecen los referentes del pasado -el cañamazo tanto de la memoria como de la ficción (¿acaso recordar no es una forma de novelar?)-, ponen encima del tablero, también de una manera paradigmática, el hecho de que la ficción -o el recuerdo- tiende a crear unas estructuras que, remitiendo a un 
ayer -aun sin forma, sin una ilación-, cuyo sentido se quiere escrutar, descifrar, conocer... o inventar/imaginar, apuntan hacia un doble orden: el de la fábula - una historia contada/estructurada episódica, ordenadamente- y el de una anhelada realidad histórica, político, social..., cuya virtualidad ha de depender de que sean superadas las contradicciones del pasado, condición sine qua non para poder establecer en el presente/futuro una nueva reestructuración, una fábula que haga vivible, more imaginario, el mañana. Tal el reto que aguarda a la Europa de las Naciones.

Orden y lógica... como pide la mente fría de quienes no aspiran a dejar las cosas en el mismo sitio de siempre, sino donde deben estar. Mente fría que ha de estar imbuida de una imaginación, de inventiva. Aparece así la razón visionaria, el imperativo categórico -que sobrepasa a la instancia ética kantiana- de sustituir el desorden de las estructuras socio-políticas y económicas de un mundo de fragmentos por el nuevo orden del conjunto.

Crear una nueva estructura bajo el signo que alienta la idea de conjunto es como escribir, pongo por ejemplo, los capítulos de una novela o pintar un mural. Porque hay que presentar una ilación lógica, una ilación que está sustentada en el principio de sucesión episódica y de interrelación, condición que aboca a la idea de conjunto.

Frente al principio por el que aboga Gilles Deleuze, en Proust y los signos: «No hay Logos, sólo hay jeroglíficos» (Deleuze, 1970: 185), el razonamiento dialéctico de Peter Gay, en Style in History: «Historical narration without analysis is trivial, historical analysis without narration is incomplete» (en White, 1992: 21).

El acto de rememorar coincide con la intención de todo narrador, sea novelista o historiador. Esa intención compartida conduce a los diversos discursos a potenciar el mensaje con unas estrategias discursivas que subrayen y hagan lo más plástico y comprensible posible lo que hay en la realidad, en el referente socio-histórico -o si falta, se inventa, se imagina-. Pero, por una parte, no siempre se consigue ese efecto; y, por otra, la solución es puramente discursiva -corresponde a la esfera del factor heurístico- y si bien se la quiere relacionar con el referente -se pretenda que lo recordado es una copia de lo acaecido-, puede, si se falla en el arte de narrar, resultar extraña al referente -a lo acaecidoy terminar, al cabo, por segregarse, por convertirse en una unidad desgajada, en una disonancia. Así se rompe uno de los principios básicos de la narrativa, el principio de que todas las partes han de estar conjuntadas -en un orden que, si no es el de la realidad, es al menos una reordenación narrativa de la realidad-. Se trata de un principio -al que se puede llegar por diversos caminos- impuesto por uno de los objetivos también esenciales de la narrativa: la transmisión de sentido - «la passion du sens», en la jerga de Roland Barthes-.

Anales, 21, 2009, pp. 39-66 
Coincidiendo con Barthes, Peter Brooks, en Reading for the plot, señala que los «plots», las tramas novelescas «are not simply organizing structures, they are also intentional structures, goal-oriented and forward-moving» (Brooks, 1985: 12). Pero, claro, no todo acaba ahí, porque a renglón seguido uno se dice, sí, bien... pero ¿cómo conjugar ambos objetivos? O para plantear el problema en otros términos, los que propone Hayden White: ¿Cómo conjugar la meta de imparcialidad, de objetividad, que debe presidir toda escritura, histórica o literaria, con la inescapable tendencia a moralizar? (White, 1992: 35-37).

Tu mano, Macbeth, es ya solamente pasado. Pero tu daga ha marcado el futuro. El tuyo y el de la corte de aquella Escocia en la que reinaba Duncan. «Let not light see my black and deep desires», pero otro deseo tuyo pudo más, era más fuerte; y la daga que usaste para llevar a cabo el regicidio pidió más sangre, generó más violencia. «These deeds must not be thought / After these ways; so, it will make us mad» (Macbeth, II, II). Ése era el deseo de la mente perturbada de lady Macbeth.

Ella y Macbeth, su marido, estuvieron presos de la memoria, antes que les llegara la infame muerte. Y ella y él, para enseñanza de toda daga asesina, no acertaron en su pronóstico: "That memory, the warder of the brain,/ Shall be a fume, and the receipt of reason / A limbeck only...» (Macbeth, I, viII).

\section{BIBLIOGRAFÍA}

«La "horda roja"», España Republicana, Buenos Aires, 18 de enero de 1941.

ABELLA, Rafael (1978), Por el Imperio hacia Dios. Crónica de una posguerra (19391955), Barcelona, Planeta.

ARISTÓTELES (1995), Etica Nicomáquea, Barcelona, Planeta, 1995.

- (1993), Parva naturalia, Madrid.

AUSTER, Paul (1995), Smoke \& Blue in the face, Barcelona, Anagrama, 1995.

BARRIO GUTIÉRREZ, José (1984), Int. a Protágoras y Gorgias, Fragmentos y testimonios, Barcelona, Orbis.

BARTHES, Roland (1982), «Le discours de l'histoire», Poétique, 49.

BERGER, John (1984), And our faces, my heart, brief as photos, Londres, Writers and Readers.

- (1995), Another way of telling, Nueva York, Vintage Books.

- (1979), Ways of seeing, London, Penguin Books.

BROOKS, Meter (1994), Psychoanalysis and storytelling, Oxford, Blackwell.

- (1985), Reading for the Plot. Design and Intention in Narrative, Cambridge, Harvard UP. 
CAUDET, Francisco (2000), Int. a Max Aub, Campo de los almendros, Madrid, Castalia.

CHIARAMONTE, Nicola (1986), The paradox of History, Filadelfia, University of Pennsylvania Press.

COOPER, Norman (1976), «La Iglesia: de la "Cruzada" al cristianismo», en Paul Preston (ed.), España en crisis: la evolución y la decadencia del régimen de Franco, Madrid, Fondo de Cultura Económica.

DELEUZE, Gilles (1970), Proust y los signos, Barcelona, Anagrama.

EDWARDS BELLO, Joaquín, «Emigrantes», La Nación, 9 de septiembre de 1939.

FERRÁNDIZ ALBORZ, F., «¿Qué será de España?», España Republicana, 30 de agosto de 1957.

FONTANA, Josep (1986), «Reflexiones sobre la naturaleza y las consecuencias del franquismo», en F. Fontana (ed.), España bajo el franquismo, Barcelona, Crítica.

GALLO, Max (1971), Historia de la España franquista, París, Ruedo Ibérico.

GOETHE (2007), Faust, Munich, Verlag C. H. Beck.

HEINE, Hartmut (1990), «Tipología y características de la represión y violencia políticas durante el período 1939-1961», en J. Tusell, A. Alted y A. Mateos (coord.), La oposición al régimen de Franco. I, Madrid, UNED.

LLEDÓ, Emilio (1994), Memoria de la ética, Madrid, Taurus.

MALCOLM, Norman (1970), «Memory and representation», Noûs, 4, 1.

MARTÍNEZ ALIER, Juan (1978), «Notas sobre el franquismo», Papers, nº 8.

MARTÍNEZ LEAL, J. y F. MARTÍNEZ SÁEZ (1995), «Alicantinos en el exilio americano», A. Girona y M. ${ }^{a}$ F. Mancebo (eds.), El exilio valenciano en América. Obra y memoria. Valencia: Inst. Juan Gil-Albert/Universitat de Valencia.

MOLINERO, Carme (1990), «Luchas obreras y oposición al franquismo en la Cataluña de la posguerra», en J. Tussell, A. Alted y A. Mateos (coord.), La oposición al régimen de Franco, I, Madrid, UNED.

NERUDA, Pablo (1974), Confieso que he vivido, Barcelona, Seix Barral.

PASCUAL BUXÓ, José (1995), «Las alas de Ícaro», en Poesía y exilio. Los poetas del exilio español en México, ed. R. Corral, A. Souto Alabarce, J. Valender, México, El Colegio de México.

SAID, Edgard (1984), «The mind of Winter. Reflections on life in exil», Harper's Magazine, septiembre.

SINGER, Wolf (1994), «Keine Wharnehmung ohne Gedächtnis», Theaterschrift, 8.

TUÑÓN DE LARA, Manuel (1947), «La crisis ideológica del franquismo», Independencia, núm. 7, 31 de mayo de 1947. 
WHITE, Hayden (1992), El contenido de la forma, Barcelona, Paidós.

ZAMBRANO, María (1933), «Nostalgia de la tierra», Tiempo Presente.

Fecha de recepción: 1 de junio de 2008

Fecha de aprobación: 10 de octubre de 2008. 